\title{
Intrasternal Route of Administration
}

National Cancer Institute

\section{Source}

National Cancer Institute. Intrasternal Route of Administration. NCI Thesaurus. Code C64988.

Injection of a medicinal product into the bone marrow of the sternum. 